\title{
BMJ Open Factors that influence the risk of falling after spinal cord injury: a qualitative photo-elicitation study with individuals that use a wheelchair as their primary means of mobility
}

Hardeep Singh (1) , ${ }^{1,2}$ Carol Y Scovil, ${ }^{2,3}$ Karen Yoshida, ${ }^{1,4}$ Sarah Oosman,
Anita Kaiser, ${ }^{1,2,6}$ Catharine Craven, ${ }^{1,2,7,8}$ Susan Jaglal, ${ }^{1,2,4,8}$ Kristin E Musselman ${ }^{1,2,4,5}$

To cite: Singh H, Scovil CY, Yoshida K, et al. Factors that influence the risk of falling after spinal cord injury: a qualitative photo-elicitation study with individuals that use a wheelchair as their primary means of mobility. BMJ Open 2020;10:e034279. doi:10.1136/ bmjopen-2019-034279

- Prepublication history for this paper is available online. To view these files, please visit the journal online (http://dx.doi. org/10.1136/bmjopen-2019034279).

Received 13 September 2019 Revised 26 November 2019 Accepted 18 December 2019

Check for updates

(C) Author(s) (or their employer(s)) 2020. Re-use permitted under CC BY-NC. No commercial re-use. See rights and permissions. Published by BMJ.

For numbered affiliations see end of article.

Correspondence to Dr Kristin E Musselman; Kristin.Musselman@uhn.ca

\section{ABSTRACT}

Introduction Falls are a concern for wheelchair users with spinal cord injury (SCl). Falls can negatively impact the physical and psychological well-being of fallers. To date, the perspectives of wheelchair users with lived experiences of $\mathrm{SCl}$ on the contributors to falls has been understudied. Information about factors that influence fall risk would guide the development of effective fall prevention strategies.

Objectives To gain a comprehensive understanding of the factors that influenced the risk of falling as perceived by wheelchair users with $\mathrm{SCl}$.

Design A qualitative study using photo-elicitation interviews. Setting A Canadian SCI rehabilitation hospital and the participants' home/community environments.

Participants Twelve wheelchair users living in the community with chronic SCl.

Methods Participants captured photographs of situations, places or things that they perceived increased and decreased their risk of falling. Semistructured photo-elicitation interviews were conducted to discuss the content of the photographs and explore perceptions of fall risk factors. A hybrid thematic analysis and the Biological, Behavioural, Social, Economic, and Environmental model were used as a framework to organise/synthesise the data.

Results Overall, the findings indicated that the risk of falling was individualised, complex and dynamic to each person's life situation. Four main themes were revealed in our analysis: (1) Falls and fall risk caused by multiple interacting factors; (2) Dynamic nature of fall risk; (3) Single factors were targeted to reduce falls and fall-related injuries; and (4) Fall prevention experiences and priorities.

Conclusions Each wheelchair user encountered numerous fall risk factors in their everyday lives. Information from this study can be used to set priorities for fall prevention. Fall prevention initiatives should consider a wheelchair user's fall risks in a holistic manner, acknowledging that a person's current situation, as well as anticipating their fall risks and fall prevention needs, will change over time.

\section{INTRODUCTION}

Falls can have significant adverse consequences such as fractures, head injuries and
Strengths and limitations of this study

- Photo-elicitation allowed detailed visual and verbal insights into the factors that influence falls experienced by wheelchair users with spinal cord injury.

- Telephone interviews may have reduced the depth/ detail of information collected.

- Photographs captured by caregivers may have influenced the content of the photographs.

- Photo-assignment instructions provided to participants prior to taking photographs may have influenced the photographs captured by participants.

- As the sample is from an urban Canadian environment, the transferability of findings to other environments/contexts is limited.

a negative impact on an individual's psychological and emotional health. ${ }^{1-3}$ Falls pose a significant complication for communitydwelling wheelchair users with spinal cord injury (SCI) as $69 \%$ (95\% CI $60 \%$ to $76 \%$ ) will experience at least one fall within a year. ${ }^{4}$

Wheelchair users commonly experience falls during transfers, reaching, propelling on an uneven surface, moving in bed and showering. ${ }^{1} 2566$ Depending on the level and severity of their SCI, some individuals primarily use a wheelchair for mobility but can also walk short distances. ${ }^{7}$ As such, some wheelchair users may experience falls while standing and walking. ${ }^{18}$ The majority of prior studies examining falls among wheelchair users with SCI used quantitative surveys to gather information on falls, which limits the breadth of information collected. ${ }^{4}$ There remains a need to gain a more detailed understanding of the nature of falls in regard to this particular population. ${ }^{24}$ Few studies have used qualitative or mixed methods to explore the perspectives of wheelchair users with SCI 
concerning the causes and the impacts of falls. ${ }^{139} \mathrm{An}$ in-depth exploration from the perspectives of wheelchair users can provide insight into priorities and potential strategies for fall prevention. ${ }^{34}$

In order to deliver effective fall prevention interventions and minimise the impact of falls and fall risk on individuals living with SCI, a comprehensive understanding of their fall prevention needs and priorities is needed. ${ }^{10}$ One qualitative methodology that enables detailed insight into the perspectives of participants on a particular issue is photo-elicitation interviewing (PEI), which involves the incorporation of photographs into an interview. ${ }^{11}{ }^{12}$ In a previous study, PEI was used to examine the perceived causes of falls and impact of fall risk on the mobility and physical activity levels of individuals with incomplete SCI. ${ }^{3}$ However, since the study sample was limited to individuals with motor incomplete SCI (ie, American Spinal Cord Injury Association Impairment Scale (AIS) grades $\mathrm{C}$ and $\mathrm{D}$ ), more research is needed to understand the factors that contribute to falls in individuals with motor complete SCI (ie, AIS grades A and B). Photo-elicitation is suited for addressing this knowledge gap. Through photo-elicitation, we can obtain a visual display of the participants' experiences, situations and environments, as well as a verbal account of their experiences with falls/ fall risk factors. ${ }^{3}$ As the perspectives of wheelchair users with SCI regarding the factors that increase and decrease their risk of falling remain understudied, here we used PEI to gain a more detailed understanding of: (A) the various risk factors associated with falls and (B) the strategies that can reduce their fall risk.

\section{METHODS}

\section{Settings and participants}

This interpretive qualitative study was conducted at the Lyndhurst Centre, Toronto Rehab - University Health Network. This study is part of a larger research study in which we tracked falls for 6 months in 65 participants with SCI (32 wheelchair users and 33 ambulators). ${ }^{8}$ Participants with the following traits were eligible for the larger study: (1) chronic ( $\geq 1$ year postinjury), traumatic SCI with a neurological level between C1 and L1 (AIS grades A-D); (2) community-dwelling for $\geq 1$ month; and (3) $\geq 18$ years of age. To recruit participants for the larger study, HS contacted individuals from the central recruitment database at the Lyndhurst Centre. This database contains a list of individuals with SCI who consented to receive information about research studies. ${ }^{13}$ In addition, recruitment flyers were posted in outpatient rehabilitation clinics, as well as on the SCI Ontario website, social media and magazine. We also asked participants to share the study information with their peers with SCI. Purposive sampling, whereby participants were 'intentionally selected to represent some explicit predefined traits', ${ }^{14}$ was used to select participants for the current study. From the larger study sample of 32 community-dwelling wheelchair users with chronic SCI, ${ }^{8}$ purposive sampling ${ }^{14}$ was used to select participants based on the following predefined traits: (1) used a manual or power wheelchair for $\geq 4$ hours per day ${ }^{15}$ and (2) had $\geq 1$ fall in the past 6 months. Based on previous studies using PEI, ${ }^{316-18}$ it was determined that 10-12 participants who met the above criteria were needed. Thus, the first 15 participants that completed the larger study and met the current study's inclusion criteria were invited to participate; 12 participants agreed.

All participants provided informed consent (verbal and written) to participate in this study. Ethical issues related to photography were reviewed with each participant at study outset. ${ }^{19}$

\section{Patient and public involvement}

Patients or the public were not involved in the design, reporting or dissemination of our research.

\section{Data collection}

As part of the larger study participants had seven to nine telephone interactions with HS. Participants were provided with verbal instructions to capture photographs of things, places or situations they perceived increased or decreased their risk of falling. Participants were provided with the following written photo-assignment instructions. 'Please take at least 2 photographs for each of the following questions: (1) What increases your likelihood of falling? and (2) What decreases your likelihood of falling?'. Participants were also instructed to refrain from taking pictures of people under the age of 18 years. They were asked to complete this photo-assignment over seven consecutive days. If participants had difficulty holding and/or manipulating the camera, they could ask a caregiver for assistance. Following photo-taking participants completed an audio recorded interview (face to face $(n=9)$ or telephone $(n=3))$ with a researcher $(H S)$ who is a female $\mathrm{PhD}$ candidate and an occupational therapist with experience in SCI rehabilitation and qualitative research. Photographs were used as a point of reference to facilitate these discussions. ${ }^{20}$

The SHOWeD framework-a set of five open-ended questions-was used to explore the issues presented in the photographs. ${ }^{21}$ The framework effectively facilitates interviews because it moves the discussion about the issue from a superficial to deeper level. ${ }^{22}$ Additional semistructured questions were asked during the interviews to clarify and gain more details on the factors perceived to contribute to the situations where participants fell (see box 1). Interview questions were added or modified to further explore ideas and concepts raised in previous interviews (eg, participants' thoughts on wheelchair safety features). ${ }^{23}$

\section{Data analysis}

The audio recorded interviews were anonymised and transcribed by the interviewer (HS) using Dragon Dictation transcription software (Dragon Professional, Nuance, Burlington, Massachusetts, USA) and then uploaded into 


\section{Box 1 Sample photo-elicitation interview questions ${ }^{21}$}

\section{SHOWeD interview questions}

1. What do you See here?

2. What is really Happening here? (Probe: What does the picture represent to you? What is happening that caused you to take this photo?)

3. How does this relate to Our lives? (Probe: How does this issue or factor impact your life?)

4. Why does this situation, concern or strength exist?

5. What can we Do about it? (Probe: How do you think the situation could be improved?)

\section{Semistructured interview questions}

1. What caused or contributed to the falls that you have experienced in the past 6 months?

2. What strategies do you use to prevent falls?

3. Please describe any fall prevention training you received while in rehabilitation?

4. How can rehabilitation better prepare you for falls in the community?

5. What are your thoughts about antitippers and seatbelts for preventing falls?

NVivo 12 qualitative data management software (QSR International Ltd). Transcripts were analysed using a hybrid thematic analysis. ${ }^{24}$ The photographs were used in the data analysis ${ }^{25}$ to aid the researcher's understanding of the factors that increase or decrease a wheelchair user's risk of falling. HS, KEM and CYS independently reviewed 7 of the 12 transcripts and discussed their interpretations of the inductive coding scheme. KEM is a scientist and licenced physical therapist with experience in quantitative and qualitative SCI research. CYS is a rehabilitation engineer, SCI knowledge mobilisation specialist and assistive technology consultant. Line-by-line inductive coding was done for the remaining transcripts by two coauthors (HS and KEM). The relationships and patterns among initial codes led to the formation of this study's preliminary themes. ${ }^{24}$ Lastly, the inductive codes within theme 3 were organised into categories of the Biological, Behavioural, Social, Economic, and Environmental (BBSE) Model. ${ }^{26}$ This model was used to identify fall-related risk factors in four categories: biological, behavioural, social and economic, and environmental. Biological factors are related to the body (ie, intrinsic), whereas behavioural, social and economic, and environmental factors relate to the outside world (ie, extrinsic) ${ }^{26}$

\section{Rigour and credibility}

Several methods were integrated throughout our research to enhance trustworthiness: (1) multiple data collection sources were used (ie, photographs and verbal interviews); (2) the data analysis process involved triangulation whereby multiple authors contributed to theme development; (3) photographs and quotes from participants were used to ensure interpretations were grounded in the data; (4) our analysis approach was reviewed by coauthors (KY and $\mathrm{SO}$ ) that were not directly involved in the analysis process to ensure confirmability of interpretations (ie, analytic probing); and (5) an audit trail of the data collection and analysis process was used to enhance transparency and accountability. ${ }^{27-30}$

\section{RESULTS}

Twelve wheelchair users with chronic SCI participated; three participants used power wheelchairs and nine used manual wheelchairs for their primary means of mobility. While all participants used a wheelchair for their primary means of mobility, three participants (P1, P6 and P12) ambulated to some extent (eg, short distances in their home). Three participants (P1, P3 and P11) received some assistance from a caregiver for taking photos. See table 1 for participant demographics.

Table 1 Participant demographics, wheelchair type, SCI details and the number of falls in the past 6 months

\begin{tabular}{llllllll}
\hline $\begin{array}{l}\text { Participant } \\
\text { code }\end{array}$ & Sex & $\begin{array}{l}\text { Type of } \\
\text { wheelchair }\end{array}$ & $\begin{array}{l}\text { 5-year age } \\
\text { category }\end{array}$ & $\begin{array}{l}\text { 5-year time } \\
\text { since injury } \\
\text { category }\end{array}$ & $\begin{array}{l}\text { Neurological } \\
\text { level of injury }\end{array}$ & AIS & $\begin{array}{l}\text { \# of falls in } \\
\text { past } \mathbf{6} \text { months }\end{array}$ \\
\hline P1 & M & Power & $55-59$ & $40-44$ & Cervical & C & 1 \\
P2 & F & Manual & $20-24$ & $5-9$ & Thoracic & B & 6 \\
P3 & M & Power & $45-49$ & $0-4$ & Cervical & B & 2 \\
\hline P4 & F & Manual & $40-44$ & $15-19$ & Thoracic & A & 2 \\
P5 & F & Manual & $35-39$ & $15-19$ & Thoracic & A & 1 \\
P6 & M & Manual & $25-29$ & $5-9$ & Cervical & C & 1 \\
P7 & F & Manual & $45-49$ & $35-39$ & Thoracic & B & 1 \\
P8 & F & Manual & $45-49$ & $25-29$ & Lumbar & C & 1 \\
P10 & F & Manual & $50-54$ & $30-34$ & Thoracic & B & 1 \\
P11 & M & Manual & $30-34$ & $15-19$ & Thoracic & C & 2 \\
\hline
\end{tabular}

AIS, American Spinal Cord Injury Association Impairment Scale; F, female; M, male; SCI, spinal cord injury. 


\section{Multifactorial and dynamic fall risk}

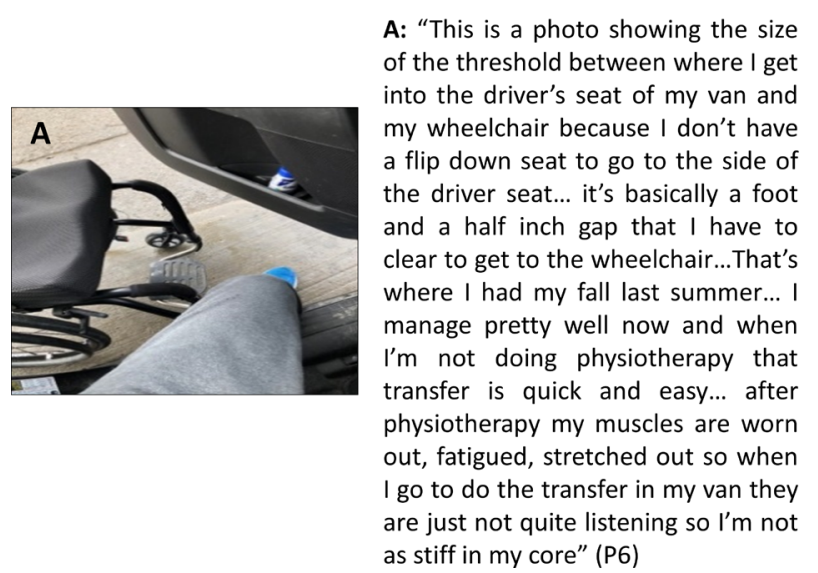

A: "This is a photo showing the size of the threshold between where I get the driver's seat of my van and my wheelchair because I don't have down seat to go to the side of driver seat... it's basically a foo a half inch gap that I have to where I had my fall last summer... manage pretty well now and when I'm not doing physiotherapy that physiotherapy my muscles are worn out, fatigued, stretched out so when are just not quite listening so I'm not as stiff in my core" (P6)

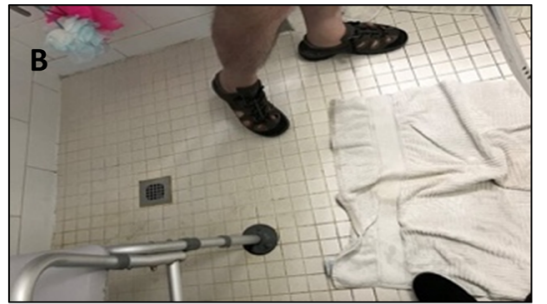

B: "This picture is just me coming out of the shower...I have to wear water shoes getting in and out of any surface where I don't have shoes on. My feet are really sensitive at the bottom...can cause more spasm in my legs and I tend to be more at risk of a fall in that case.... when I was younger post-injury it, I could get around better with bare feet." (P1)

Figure 1 Multifactorial and dynamic fall risk.

\section{Overarching theme: Individualised, dynamic and complex fall risk factors}

Participants recognised that their risk of falling was specific to their current situation and that it was dynamic (ie, constantly changing) with respect to changes in their intrinsic and extrinsic environments. To complicate matters, a wheelchair users' risk of falls was influenced by a complex interplay of multiple factors (see figure 1).

Consequently, the factors that decreased their risk of falling were developed through previous experiences of falls and tailored to their current situation. In addition to the overarching theme, four main themes were revealed: (1) Falls and fall risk caused by multiple interacting factors; (2) Dynamic nature of fall risk, (3) Single factors were targeted to reduce fall risk and fall-related injuries; and (4) Fall prevention experiences and priorities (see table 2 and figure 2).

\section{Theme 1: Falls and fall risk caused by multiple interacting factors}

Falls were primarily caused by an interaction of multiple fall risk factors. In addition, participants had to constantly consider fall risk associated with their actions.

\section{Subtheme 1a: Falls and fall risk are multifactorial}

Previous falls described by participants, as well as their risk of future falls, were typically influenced by a combination of biological, behavioural, social and economic, and environmental factors, but also wheelchair factors emerged as important for fall risk. Participants provided several examples of how behavioural factors combined with an environmental hazard resulted in a fall. All participants agreed that distractions were a common contributor to falls. When rushing or multitasking, participants were distracted and paid less attention to the task and environment. Several participants recalled many experiences of their wheelchairs tripping over cracks, potholes, drainage grates, rocks or branches on the ground when wheeling outdoors while they were not paying attention to the environment. For instance, P5 described how consuming alcohol combined with a flat tire caused her to fall backwards: 'My flat tire was making me unsteady and then also I had a few drinks... it was kind of a combination of the two'. Similarly, P10 explained that a combination of speed and going through a narrow pathway could cause a fall: "people just have to be careful with their speed and the width of their chair... (the path) may be too narrow for them to pass over but sometimes when you're not thinking mistakes can happen'. A power wheelchair user explained that when obstacles or people suddenly came into his path this required him to quickly change his behaviour (ie, stop suddenly), increasing his risk of falling forward out of his wheelchair.

Participants provided examples of how economic factors combined with environmental factors increased their risk of falling. For instance, the high cost of manual wheelchair add-ons (eg, 'shock-absorbing' caster wheels and suspension caster forks) made it difficult for some participants to add safety features that could potentially increase the wheelchair's stability when faced with environmental fall hazards (eg, potholes). One participant spoke about cost preventing her from improving the accessibility and safety during vehicle transfers as she could not afford a wheelchair vehicle lift. Another participant spoke about the egregious cost of home modifications, as well as renovation restrictions he had to follow in his rental housing.

Some participants provided examples of the interaction of social and environmental factors that increased their risk of falling. For example, P9 voiced a concern with respect to receiving assistance from members of the public when trying to cross the street in the time allotted by the walk signal: "people come along and say here let me help you. And they wheel me without tilting me back and they have dumped me out of my wheelchair'.

Participants discussed several factors related to their wheelchair that when combined with other factors (ie, biological, behavioural, social and economic, and environmental) placed them in situations that increased their risk of falling. A stationary footplate was one feature perceived to be a tripping hazard when they performed transfers. Due to their size and position, narrow push rims 
Table 2 Themes, subthemes and supporting quotes

\author{
Overarching theme: Theme 1: Falls and fall risk caused by multiple interacting factors \\ Individualised, \\ dynamic and complex \\ fall risk factors
}

1a. Falls and fall risk are multifactorial

(i) 'There was a box with 12 bottles in it and I had it in my lap... And then the box shifted going over this lip and then that caused the chair to tip... my hand that barely works was securing the box and then my other hand was using the controls on my power chair... I tried to secure the box and I'm shifting my weight forward, and the chair tipped forward'. (P11)

1b. Consider fall risk associated with their actions

(i) 'I wouldn't change my chair... it's up to me to be vigilant in my surroundings... you're constantly monitoring your environments and your behaviour and your actions'. (P8)

(ii) 'I removed [the seatbelt] from my wheelchair because what I found is if I am hitting something hard enough to throw me out of my wheelchair, the seatbelt is not going to stop me. What it is going to do is bring my wheelchair with me so if I tip over with the wheelchair strapped to me then I am laying on the ground with my wheelchair on top of me that I can't get the seatbelt undone, whereas if I hit something and fall out of the wheelchair, it stays upright usually and I can at least get back into it'. (P6)

\title{
Theme 2: Dynamic nature of fall risk
}

(i) 'There was a change in situation. A change in physical situation. Having a weakened arm, I lost grip stability and strength. It became a real problem. It gives up some times. It just collapses and I just fall mid-transfer'. (P8)

(ii) 'None of the equipment was new or anything like that. I was used to doing that transfer but it is internal factors. I was disoriented, I hadn't had enough sleep, I was a new mother and these are the reasons why I had those falls'. (P4)

\section{Theme 3: Single factors perceived to reduce falls and fall-related injuries}

\section{3a. Wheelchair features}

(i) '(Gloves with a rubber sole) are the ultimate, ultimate things that I have that decrease my risk of falling... They are a huge safety net on transfers because of the grip... they help me transfer onto the floor, on equipment, pushing the wheelchair'. (P6) (see figure 2A)

ii) 'This is just a generic photo of the anti-tippers. They are a huge safety thing and what decreases the likelihood of falling'. (P6) (see figure 2B)

\section{3b. Environmental factors}

(i) 'This is the ideal way the pavement gaps should line up... no huge gaping there... this has zero risks for me to fall'. (P4) (see figure 2C)

(ii) 'This proper sidewalk provides the safety of not having a fall... (It has) proper cut outs, button placement, no dips or uneven ground. Proper grades and...not having to go backwards off a curb'. (P12) (see figure 2D)

3c. Behavioural factors

(i) 'Trust your feelings. When you feel it is not safe don't do it; don't do it because your body, your body will tell you when it's safe to do it. If you do something dangerous or if you find it's not safe to do something just stop yourself there'. (P7)

3d. Biological factors

(i) 'l've lost weight and am continuing to lose weight so that's helping'. (P1)

3e. Social and economic factors

(i) 'I just don't walk on my own because if I need a wheelchair I need it fast and anyone that's assisting me they have been trained to bring my chair for me and to help me to land fairly gently if that's an option'. (P1)

\section{Theme 4: Fall prevention experiences and priorities}

4a. Training inappropriate for dynamic needs

(i) 'The focus was on getting up and getting mobile and not so much the whole fall prevention'. (P1)

(ii) 'I never thought of having to go back into the chair in a regression... I was taught fall prevention of how to use a walker and how to use my walking poles but I guess because we were so focused on me walking, myself and everyone included, [fall prevention skills] was sort of missed'. (P12)

4b. Priorities for fall prevention initiatives

(i) 'You tuck your chin in and you lean forward when you feel yourself going back and that takes practice. So like it was during basketbal and we have access to these huge mats. So my friend had me just go up and park my chair without my brakes, and lean back and feel comfortable just falling on it and getting used to it that. So it's putting me in that situation where l'm going to fall no matter what and where I'm making myself fall so if that happens it's muscle memory and not just me going oh my gosh I'm falling and you know flailing and hitting my head'. (P12)

(ii) 'Taking people out in the community and going over sidewalks is a good idea. Teaching them how to do wheelies and navigate steep curves or steep ramps would also prevent them hitting the bottom and flying forward. So making sure people leave the rehab centre with the confidence to perform a wheelie to get down a steep curb. Also, training people on good transfers in the washroom because when you're wet or slippery or anything like that, you are at a higher risk of falling'. (P5)

were another feature that made it difficult for the manual wheelchair user to form a stable grip when performing a transfer or leaning to the side or forward. P6 explained that without a stable grip on the push rim, 'it's more likely for [him] to tip over'. Small casters were another problematic wheelchair feature as they became stuck in small cracks on the ground or caused the wheelchair to become unstable when rolling over debris in the environment. Although larger casters were perceived to be more stable than smaller casters, there was a general consensus that larger casters reduced, but would not eliminate, their wheelchair tripping over obstacles on the path. Low tire 

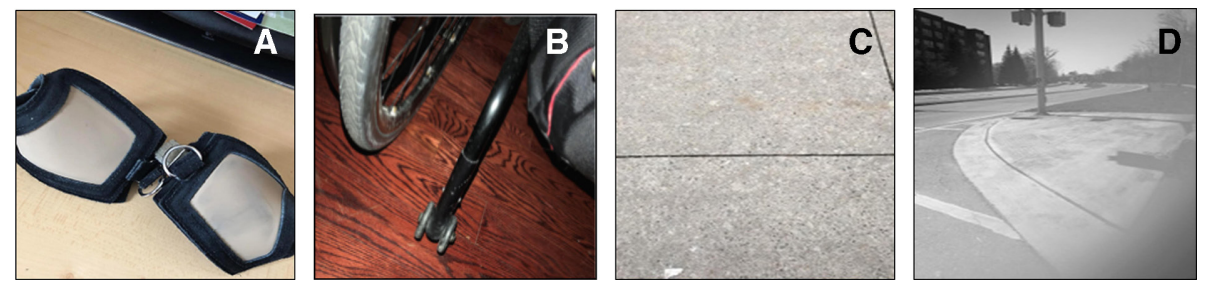

Figure 2 Single factors perceived to reduce falls and fall-related injuries. A) Gloves with a rubber sole used to increase grip during transfers; B) Anti-tippers on a manual wheelchair; C) Sidewalk with ideal pavement gaps; D) Ideal intersection for safe mobility

pressure and loose wheelchair brakes became fall hazards during transfers, as they caused the wheelchair's centre of gravity to shift. Many participants explained how an ill-fitting wheelchair significantly increased the risk of falling. P2 attributed experiencing multiple falls during the early years living with her SCI as her first wheelchair was, 'eight inches too wide' and she was told by the wheelchair prescriber that '[she] would grow into it'.

\section{Subtheme 1b: Consider fall risk associated with their actions}

Participants had to constantly consider fall risk associated with their actions. There were instances where participants were aware that certain activities or decisions could increase their risk of falls, but they still decided to participate in the activity. For example, most manual wheelchair users did not wear a seatbelt while they were in the wheelchair. As a manual wheelchair user, P9's preference for not wearing a seatbelt was related to preventing pressure injuries: 'I have to lift myself up for pressure sores. So if I had a seatbelt on, it would be an extra burden'. Some other manual wheelchair users believed falling while wearing a seatbelt increased their chance of injury as the wheelchair would fall on top of them.

Despite supporting antitippers as safety features that could prevent falls, some participants chose not to use them because antitippers restricted their independence/ autonomy and their ability to access certain areas within the community. For instance, antitippers restricted the ability to perform wheelies when overcoming high curbs, interfered with going up inclines, and were incompatible with some vehicle lifts. Also, participants described a negative stigma associated with using more adaptive aids, and consequently, many participants decided to remain 'minimalistic' with their use of adaptive devices, despite this decision potentially increasing their fall risk. For example, P2 explained that she chose not to use antitippers because of the stigma associated with them. P4 shared that antitippers made a wheelchair user look like a novice and resembled training wheels on a bike. Some participants used antitippers during the early stages of their SCI or when they were adjusting to a new wheelchair. However, once they became more comfortable with the wheelchair, the antitippers were removed. Stigma was also a barrier to adopting other types of safety equipment. For instance, although P6 recognised that a flip down seat would improve the safety of his car transfers, he chose to avoid using it: 'the more equipment I have, the more disabled I feel. I find even if it does help me, I am still stubborn like that'.

Participants chose to consume alcohol in social situations, despite alcohol leading to decreased balance and inattention to the environment, sometimes resulting in a fall. P5 explained: '[alcohol] decreases my coordination... I am just more relaxed and leaning back and tip over... in 20 years the only time I have hit my head was a few weeks ago and I blame the red wine'. Similarly, some participants chose to wheel on uneven environments during leisure activities, despite uneven ground increasing their chance of falling. For instance, P1 recalled, 'I've fallen out of my chair a couple of times over the years... doing really ridiculous things like coming down a grass hill, skidding sideways and stuff like that'.

For participants that could ambulate short distances they described falls related to their legs 'giving out' or their knees buckling unexpectedly while in an upright standing position. Although P1 had poor balance, he continued to ambulate short distances as it was important for managing his pain, preventing pressure injury, maintaining good circulation and muscle tone. Similarly, leaning/reaching was required to complete activities of daily living; however, when participants reached above their head or leaned 'too far' forwards, backwards or sideways, they could easily fall. Based on their physical abilities, each participant had a different notion of what was 'too far'.

\section{Theme 2: Dynamic nature of fall risk}

The dynamic nature of falls was highlighted in many situations described by the participants. For instance, there was a period of increased falls when participants began using new equipment such as a wheelchair, wheelchair cushion, bed or chair. P10 recalled how gruelling it was to learn and adjust to the features of her new manual wheelchair: 'every time I have a wheelchair that's new, I usually have to fall a couple of times... to figure out where a safe place is to put my hands when I transfer, the weight of the chair, the centre of gravity'.

Based on their previous experiences, participants believed they were at an increased risk of falling when they had a decline in their physical or psychological health. Participants explained that illness or injury could decrease their muscle strength, physical endurance, tolerance and dynamic balance, and these intrinsic factors increased their chances of falling. For instance, chronic 
shoulder issues due to overuse decreased P9's stability and balance during transfers from her manual wheelchair. Furthermore, secondary complications related to ageing with an SCI were perceived to increase the risk of falling. For example, P1 explained that he experienced a greater number of spasms in his legs as he aged.

Also, fatigue from physical activity, psychological stress and/or a lack of sleep were perceived to contribute to falls because fatigue increased participants' chances of making errors during movement. P6 found he was at an increased risk of falling after his physiotherapy sessions because he felt, 'fatigued, stretched out' and 'when I go to do the transfer in my van, [my muscles] are just not quite listening. I'm not as stiff in my core... I don't have the strength or my coordination'.

\section{Theme 3: Single factors were targeted to reduce fall risk and fall-related injuries}

While the contributors to falls and fall risk were multifactorial, the strategies suggested to reduce the participants' risk of falling commonly addressed a single factor. Box 2 lists fall prevention strategies based on recommendations and strategies highlighted by participants in this study.

\section{Subtheme 3a: Wheelchair features \\ Manual wheelchair features}

In addition to possessing a correctly fitted wheelchair, participants offered several recommendations to reduce fall risk while using a manual wheelchair. Wider push rims enabled the wheelchair user to hold on to the rim for extra support when they leaned or reached, thereby reducing fall risk. Seat 'dump', which is when the rear part of the seat is lower than the front part of the seat, was particularly important for those with poor core strength or who had recently sustained an SCI. Large-sized casters with a shock absorbing feature that minimised shock when rolling over uneven ground or descending/ ascending curbs were also mentioned. A flip up footplate that provided more space for leg clearance when performing a transfer was recommended. Participants also stressed that it was essential that the wheelchair user regularly maintained their wheelchair (ie, brakes and tire pressure) to reduce mechanical problems, which could contribute to fall-related accidents/injuries. There was discussion of how the added weight and/or width made manoeuvrability more complicated and strenuous. P8 explained,

You gotta get a chair that fits you. Custom to your body shape and function level, that is light, that you can transfer in and out of your car and do all those things. So it's a toss up... I could get a tank and have wheels that are five times as big as this and the chair would weigh 300 pounds, but that would limit my independence... it's a fine balance of having a chair that's light and fits you and is mobile.

The majority of manual wheelchair users agreed that installing antitippers on a wheelchair prevented
Box 2 Strategies to reduce fall risk from the perspectives of wheelchair users with spinal cord injury

\section{Strategies to reduce the risk of falling related to the wheelchair:}

1. Regular maintenance of wheelchair (eg, brakes and tire pressure).

2. Large diameter casters.

3. Shock absorbing casters.

4. Push rims should be wide enough to allow stable grip when reaching/leaning.

5. Ensure wheelchair fits user appropriately.

6. Increase seating dump if falling forward is a concern.

7. Grip gloves to increase stability for transfers and reaching/leaning.

8. Use seatbelts and chest straps when using a power wheelchair.

9. Explore the benefits and drawbacks of using antitippers and seatbelts; use of these safety features should be an informed choice by wheelchair users.

\section{Strategies to reduce the risk of falling in the home environment:}

1. Ensure grab bars are appropriately positioned in the washroom.

2. A roll-in shower with a drain that does not require sloping tiles.

3. An outdoor ramp with drain holes to reduce rain/snow build up.

Behavioural strategies to reduce fall risk and minimise injuries:

1. Continuously scan the environment and beware of small cracks/ uneven spots in pavement.

2. Inspect surfaces prior to transfers.

3. Take more time during physical tasks (eg, transfers) to avoid rushing.

4. Be aware of body signs (eg, levels of fatigue, pain and weakness).

5. Advocate for removal of community fall hazards.

6. Tuck chin in when falling backwards to reduce chances of a fallrelated injury.

7. Twist to the side when falling forwards to reduce chances of a fallrelated injury to the hands/wrists.

8. Be self-aware of changing care needs due to illnesses/injuries.

9. Take the time to become familiar with new equipment (eg, a wheelchair, cushion and bed).

10. Learn from causes of previous falls (eg, understand what caused the fall and how to minimise fall risk).

11. Ask a peer for fall prevention tips.

12. Understand that fall risk may increase when consuming alcohol.

13. Ensure a secure grip on the wheelchair prior to reaching/leaning.

Biological strategies to reduce fall risk:

1. Strengthen muscles and maintain range of motion/flexibility.

Socioeconomic strategies to reduce risk of falling:

1. Ask for assistance when not confident performing task.

2. Advocate for trained personal care workers.

backwards falling; however, only three of nine manual wheelchair users used antitippers to varying degrees. See figure 2 (photo B) for an image of antitippers. P9 explained:

Some people go home and put on some slippers. I switch chairs. So I have an indoor chair at home and I have anti-tippers on it... If I'm out in public, I can always get help to get up. But if I'm alone in my home, I wouldn't have anyone to help me get up. 
P8 had a negative experience wherein the antitippers failed to prevent a fall: 'I had anti-tip tubes on the back of my chair and I still fell out backwards. It didn't work'. P12 feared that falling backwards over her antitippers could lead to severe injuries.

\section{Power wheelchair features}

Seatbelts and chest straps were found to be essential safety features to prevent falls while operating a power wheelchair. P3 customised his wheelchair by adding a button activated tilting system that allowed him to independently regain postural stability after falling forward. The reclining feature of a power wheelchair enabled P3 to 'counterbalance' and compensate for positional changes caused when going up or down ramps.

\section{Subtheme 3b: Environmental factors Accessible spaces}

A good curb cut at a crosswalk was perceived to reduce the risk of falling for both manual and power wheelchair users. Participants argued that a good crosswalk possessed the following features: a crosswalk button that was within reach of a wheelchair user's arm length, had a smooth ground with gradual incline transitions and provided wheelchair users with ample time to cross the road. In addition, sidewalks must be smooth without cracks, potholes or debris (eg, rocks, branches and snow/ice) to reduce a wheelchair users' risk of falling. P5 proposed 'routine examinations' and making property owners more accountable for cleaning sidewalks around their properties.

\section{Adaptive equipment}

Grab bars in the washroom were crucial to reducing a wheelchair user's risk of falling. P5 explained that the most useful grab bar was the L-shaped grab bars as they were easier to grip than an angled grab bar. In their home, participants applied a variety of strategies to reduce their risk of falling. After experiencing multiple falls during tub transfers, one participant changed her bathtub to a roll-in shower; she also installed a drain around the perimeter of the shower that did not require sloping of the tile floor (ie, Schluter drain). Another strategy used to decrease the risk of a wheelchair shifting during transfers was resting the wheelchair on a non-slip mat.

\section{Subtheme 3c: Behavioural factors \\ Taking more time}

Taking their time when performing tasks provided wheelchair users with more time to notice and avoid a fall hazard. Power wheelchair users maintained that reducing their speed when going over door thresholds was a good preventive strategy. A fall prevention strategy mentioned by two participants when travelling was to call hotels and restaurants in advance to ensure they were easily accessible and fit their specific needs.

\section{Scanning the environment}

Constantly scanning the environment was a strategy used by all participants to avoid falls in the community. Being continuously cautious and alert of their surroundings was of utmost importance to avoiding a fall.

\section{Being an experienced wheelchair user}

Many participants believed that being a more experienced wheelchair user resulted in fewer falls. P9 explained she became better at recognising and avoiding fall risk with experience: 'The likelihood of my falling has reduced because I've pretty much been through every scenario that I could where I had come close to falling or actually fallen. So you learn from those things'. She went on to say while the number of falls she experienced were fewer than in years past, she still fell occasionally.

\section{Body awareness}

Wheelchair users explained that tuning into their current physical and mental state prior to each physical task decreased their likelihood of falling. A participant who ambulated short distances explained that his legs reacted differently to each floor surface (eg, carpet, hardwood or tile) requiring him to adjust his walking strategy for each surface to reduce his chances of falling.

\section{Advocating for removal of community fall hazards}

Advocating for city council to remove fall hazards in the community was an effective strategy previously used by some participants. It was a shared perspective that greater involvement of wheelchair users in planning the layout of public spaces would significantly reduce community fall risk and accessibility barriers.

\section{Falling the right way}

Since falls were believed to be inevitable, wheelchair users emphasised injury reduction strategies. For instance, several participants spoke about falling in a manner that prevented a head injury. When falling backward from a manual wheelchair P12 said, 'you tuck your chin in and you lean forward when you feel yourself going back. And that takes practice'. Most participants developed fall prevention strategies through receiving assistance from a therapist and drawing on prior fall experiences. P8 explained:

I was lucky that when I was in (deidentified rehabilitation centre), we were such a big group... we were just going out to try to have fun... we would flip out of our chairs and that was part of just learning to be in a chair. And we learned very quickly what to do if you fall out of your chair... I remember my physiotherapist saying if you fall, put your head down and fall backwards, roll out of your chair and also how to get back in it.

\section{Subtheme 3d: Biological factors}

There was limited discussion on biological fall prevention strategies. The fall prevention strategies discussed 
by participants pertaining to intrinsic factors included improving strength, flexibility and losing weight as doing so would make it easier to perform transfers.

\section{Subtheme 3e: Social and economic factors}

Having easy access to assistance and experienced/trained personal care workers were two aspects pertaining to social and economic factors that reduced wheelchair users' risk of falling. To reduce fall risk, many participants asked for supervision or assistance from social supports or members of the public when they were not confident in performing a task. P1 advised, 'not to become too proud to ask for help and have someone supervise while you're walking'.

\section{Theme 4: Fall prevention experiences and priorities}

Participants explained that the fall prevention training they had received was no longer appropriate for their dynamic needs and discussed priorities for fall prevention initiatives.

\section{Subtheme 4a: Training inappropriate for dynamic needs}

Many of the participants felt they did not receive comprehensive fall prevention training after sustaining an SCI. Despite being provided with fall prevention education, several participants ignored the advice they were given because they believed it was not applicable to their situation or a concern for them until they fell. For some participants, the fall prevention education they received became inappropriate due to changes in their physical abilities and function, such as transitioning from a power to manual wheelchair or from being ambulatory to using a wheelchair. Instead, P12 explained that fall prevention skills were learnt from a peer with SCI: "what my peer did was like getting those mats and teaching me how to fall backwards properly'.

\section{Subtheme 4b: Priorities for fall prevention initiatives}

According to the participants, the aims of fall prevention initiatives should be to inform people with SCI about fall risk factors, how they could learn from previous falls and provide them with practical fall prevention training. Wheelchair users would benefit from education about various wheelchair safety features, but their choice not to use safety features should be respected. In addition, participants would like fall prevention training to include strategies to avoid falls when using their wheelchair and during transfers and to learn how to mitigate common fall hazards in the home and community environments. P12 explained that the goal of fall prevention education was to teach wheelchair users how to minimise injury when falling; she explained in detail the 'tuck and roll' manoeuvre to protect the head. Most importantly, participants argued since 'everyone is different' fall prevention training programmes should take individual differences into account.

\section{DISCUSSION}

Photo-elicitation interviews were used to better understand the factors that increased and decreased fall risk according to wheelchair users with chronic SCI. Findings from this study suggest that each wheelchair user had a unique set of fall risk factors based on an interaction of multiple fall risk factors within their specific situation, and their risk of falling was dynamic (ie, fall prevention needs change over time). When addressing a wheelchair user's fall risk, the individualised, dynamic and complex nature of fall risk and their dynamic fall prevention needs should be considered. Participants also discussed priorities for fall prevention training, as well as multiple fall prevention strategies that they developed through their past experiences of falling.

Although individualised fall prevention approaches have been previously well supported and recommended for use with older adults, ${ }^{31}{ }^{32}$ they have been less recognised for the SCI population. The need for individualised fall prevention is not a surprising finding given that individuals with SCI boast a wide range of physical and functional abilities. ${ }^{33}$ Our findings suggest a need for fall prevention initiatives to be available throughout an individual's life and adapted to reflect one's changing needs and life circumstances.

While previous literature reports that falls are a greater concern for younger, more active individuals with SCI, ${ }^{34}$ participants in the current study highlighted ageing-related factors that increased their risk of falling. Also, changes in a person's situation, such as a temporary illness or more permanent comorbidities, impacted their fall risk.

Contrary to previous studies, ${ }^{34}$ we found that the BBSE model was not appropriate to categorise perceived fall risk in the SCI population because falls are influenced by multiple and dynamic fall risk factors that spanned across multiple categories of the model. In contrast, when participants described factors or strategies that reduced their chances of falls, these often fit within a single category of the BBSE model. When developing fall prevention interventions, attention should move beyond single factor solutions to account for the multifactorial nature of falls. Findings from a prior study support this approach to fall prevention as the authors found $70 \%$ of falls were caused by more than one fall attribution. ${ }^{1}$ In clinical practice, healthcare practitioners should consider whether individuals with SCI who are primarily wheelchair users also ambulate short distances, as wheelchair users can experience falls during standing/walking. ${ }^{18}$ Providing these individuals with fall prevention strategies that address their fall risk related to wheelchair use as well as upright activities (eg, standing/walking) may be beneficial. Furthermore, healthcare practitioners should acknowledge the multiple and interacting factors that influence a wheelchair user's fall risk that may span across multiple categories of the BBSE model. Doing so would direct the customisation of fall prevention programmes that meet each person's individual needs.

In addition, several crucial fall hazards pertaining to wheelchairs were identified. It is critical for wheelchair designers, vendors and therapists to be aware of the features that are perceived to increase and decrease the 
risk of falling when designing or prescribing wheelchairs to individuals with SCI. Therapists and vendors should include the perspectives and concerns of wheelchair users in the design and customisation of wheelchairs to account for an individual's needs and preferences.

Box 2 lists fall prevention strategies based on recommendations and strategies highlighted by participants in this study. This information can inform the development of multifactorial fall prevention strategies/education. Future research should further explore realistic and feasible fall prevention techniques/strategies that a wheelchair user can easily apply in their home and community environment.

Although an activity or decision may increase the risk of falling, participants may continue to participate in certain activities. Individuals 'make choices that have the greatest personal benefit and relevance to their lives'. ${ }^{35}$ When considering daily activities and the risk of falling, this decision-making approach was adopted by participants. For instance, despite recommendations encouraging the use of seatbelts for manual wheelchairs,$^{36}$ the majority of wheelchair users in this study chose not to use seatbelts. Furthermore, the use of antitippers among wheelchair users with SCI was variable because antitippers were seen as limiting their independence. Interestingly, this is not the first time wheelchair users have expressed a dislike for seatbelts and antitippers. ${ }^{37}$ As found in the current study, safety features that enhance a wheelchair's stability have also been previously recognised to interfere with performance and manoeuvrability, ${ }^{38}$ and when making decisions, wheelchair users may choose not to use antitippers for this reason. Making appropriate judgements to the risk of falls presented in an activity is important to decrease fall risk. To address this, the utility of a selfmanagement approach to fall prevention that targets problem-solving and decision-making skills has previously been highlighted. ${ }^{35}$

Similar to findings in previous studies, ${ }^{39}$ wheelchair users tend to develop fall prevention strategies based on their life experiences. Thus, it might be worthwhile to explore whether practising practical fall prevention techniques in a controlled and safe setting reduces falls and/ or fall-related injuries. In this study, it was suggested that peers, along with therapists, may be a valuable combination for delivering fall prevention training. Peer mentoring has been employed in interventions for individuals with $\mathrm{SCI}^{40} 41$ but has not yet been explored as a potentially viable fall prevention training method. Future research should investigate the utility of peer mentoring in fall prevention.

The limitations of this study are important to consider. Our first limitation is the use of telephone interviews. Although we used telephone interviews to accommodate the participants that could not attend in person, we recognise that the absence of visual cues in telephone interviews may have reduced the depth/detail of information collected in those interviews. ${ }^{42}$ Second, the participants that had difficulty holding and/or manipulating the camera asked a caregiver for assistance. It is possible that the caregivers may have influenced the photograph content. ${ }^{10}$ Third, although the researchers refrained from providing participants with examples of how they could respond to the photo-assignment, it is possible that the verbal photo-taking and photo-assignment instructions provided could have unintentionally influenced the content photographed by the participants. For instance, participants may have photographed fall risk factors that they assumed the researchers would be interested in rather than what they thought was most meaningful. ${ }^{10}$ Fourth, the unequal distribution of manual and power wheelchair users is important to consider. Since there were more manual wheelchair users in our sample, there was a greater focus on fall risk factors related to using a manual wheelchair. Fifth, the sex distribution of our sample (33\% men and $67 \%$ women) did not represent that of the Canadian traumatic SCI population, ${ }^{43}$ which could impact the trustworthiness of the data. However, the high proportion of women in our sample was also a strength as women tend to be under-represented in SCI research. ${ }^{44}$ Finally, since this study presents the perspectives of participants that reside in an urban Canadian environment, the findings may have limited transferability to other environments/contexts.

\section{CONCLUSION}

In conclusion, multiple and dynamic factors influenced a wheelchair user's risk of falling. A need for peer-led fall prevention/management education was highlighted in our study. To effectively address a wheelchair user's risk of falls, the complex nature of fall risk factors must be accounted for. Findings from this study hold utility for multiple stakeholders (ie, wheelchair users with SCI, clinicians, researchers, vendors and wheelchair designers) and can inform individual approaches to understanding a wheelchair user's risk of falling, as well as fall prevention strategies. Future research should actively involve participants in the development of comprehensive and effective fall prevention interventions.

\section{Author affiliations}

${ }^{1}$ Rehabilitation Sciences Institute, University of Toronto Faculty of Medicine, Toronto, Ontario, Canada

${ }^{2}$ Lyndhurst Centre, KITE, Toronto Rehabilitation Institute-University Health Network, Toronto, Ontario, Canada

${ }^{3}$ Department of Occupational Science \& Occupational Therapy, University of Toronto, Toronto, Ontario, Canada

${ }^{4}$ Department of Physical Therapy, University of Toronto, Toronto, Ontario, Canada ${ }^{5}$ School of Rehabilitation Science, University of Saskatchewan, Saskatoon, Saskatchewan, Canada

${ }^{6}$ Canadian Spinal Research Organization, Toronto, Ontario, Canada

${ }^{7}$ Division of Physical Medicine and Rehabilitation, Faculty of Medicine, University of Toronto, Toronto, Ontario, Canada

${ }^{8}$ Institute of Health Policy, Management and Evaluation, University of Toronto, Toronto, Ontario, Canada

Acknowledgements We would like to thank the participants for dedicating their time to this study.

Contributors HS participated in study design, collected and analysed the data and wrote the first draft of the manuscript. CYS participated in data analysis and 
manuscript writing. KY participated in data analysis and manuscript editing. SO participated in data analysis and manuscript editing. AK participated data collection and manuscript editing. CC participated in study design, data collection, and manuscript editing. SJ participated in study design, data collection, and manuscript editing. KEM participated in the study design, analysis and manuscript writing. All authors read and approved the final manuscript.

Funding This work was supported by the Craig H. Neilsen Psychosocial Research Grant (grant number 440070) to KEM, consulting fees paid to CYS from the Craig H. Neilsen Psychosocial Research Grant (grant number 440070) and a student scholarship from the Toronto Rehab Institute-University Health Network to HS.

Disclaimer The funders did not have a role in the study's design, execution, analyses and interpretation of the data.

Competing interests None declared.

Patient consent for publication Not required.

Provenance and peer review Not commissioned; externally peer reviewed.

Data availability statement № data are available.

Open access This is an open access article distributed in accordance with the Creative Commons Attribution Non Commercial (CC BY-NC 4.0) license, which permits others to distribute, remix, adapt, build upon this work non-commercially, and license their derivative works on different terms, provided the original work is properly cited, appropriate credit is given, any changes made indicated, and the use is non-commercial. See: http://creativecommons.org/licenses/by-nc/4.0/.

\section{ORCID iD}

Hardeep Singh http://orcid.org/0000-0002-7429-5580

\section{REFERENCES}

1 Sung J, Trace Y, Peterson EW, et al. Falls among full-time wheelchair users with spinal cord injury and multiple sclerosis: a comparison of characteristics of fallers and circumstances of falls. Disabil Rehabil 2019;41:389-95

2 Forslund E, Jørgensen V, Franzén E, et al. High incidence of falls and fall-related injuries in wheelchair users with spinal cord injury: a prospective study of risk indicators. J Rehabil Med 2017;49:144-51.

3 Musselman KE, Arnold C, Pujol C, et al. Falls, mobility, and physical activity after spinal cord injury: an exploratory study using photoelicitation interviewing. Spinal Cord Ser Cases 2018;4:39.

4 Khan A, Pujol C, Laylor M, et al. Falls after spinal cord injury: a systematic review and meta-analysis of incidence proportion and contributing factors. Spinal Cord 2019;57:526-39.

5 Nelson AL, Groer S, Palacios P, et al. Wheelchair-related falls in veterans with spinal cord injury residing in the community: a prospective cohort study. Arch Phys Med Rehabil 2010;91:1166-73.

6 Nelson A, Ahmed S, Harrow J, et al. Fall-related fractures in persons with spinal cord impairment: a descriptive analysis. SCI Nurs 2003;20:30-7.

7 Nas Ket al. Rehabilitation of spinal cord injuries. World J Orthop 2015;6:8-16

8 Singh $\mathrm{H}$, Flett $\mathrm{H}$, Hitzig S. A comparison of falls between wheelchair users and ambulators with spinal cord injury [Poster presentation]. ACRM Annual Conference. Chicago, II, 2019.

9 Jannings W. A quality improvement project to investigate the circumstances of lower limb fractures in non-ambulant persons with spinal cord injury. JARNA 2017;20:14-18.

10 LaVela SL, Balbale S, Hill JN. Experience and utility of using the participatory research method, Photovoice, in individuals with spinal cord injury. Top Spinal Cord Inj Rehabil 2018;24:295-305.

11 Harper D. Talking about pictures: a case for photo elicitation. Visual Studies 2002;17:13-26.

12 Clark-lbáÑez M. Framing the social world with Photo-Elicitation interviews. Am Behav Sci 2004:47:1507-27.

13 Verrier M, Carson J, Brisbois L, et al. Describing the feasibility, and planning for the scalability of central recruitment for patients with subacute $\mathrm{SCl}$ in tertiary academic rehabilitation centres. J Spinal Cord Med 2012;35:419-78.

14 Luborsky MR, Rubinstein RL. Sampling in qualitative research: rationale, issues, and methods. Res Aging 1995;17:89-113.

15 Rushton PW, Kirby RL, Miller WC. Manual wheelchair skills: objective testing versus subjective questionnaire. Arch Phys Med Rehabil 2012;93:2313-8.

16 Fritz H, Lysack C. "I see it now": Using photo elicitation to understand chronic illness self-management: L'usage de la méthode de photo-interview pour mieux comprendre l'autogestion des maladies chroniques. Can J Occup Ther 2014;81:247-55.

17 Shell L. Photo-Elicitation with Autodriving in research with individuals with mild to moderate Alzheimer's disease: advantages and challenges. Int J Qual Methods 2014;13:170-84.

18 Johnson CM, Sharkey JR, Dean WR, et al. It's who I am and what we eat. Mothers' food-related identities in family food choice. Appetite 2011;57:220-8

19 Lal S, Jarus T, Suto MJ. A scoping review of the Photovoice method: implications for occupational therapy research. Can J Occup Ther 2012;79:181-90.

20 Torre D, Murphy J. A different lens: changing perspectives using Photo-Elicitation interviews. Educ Policy Anal Arch 2015;23:111.

21 Wang CC. Photovoice: a participatory action research strategy applied to women's health. J Womens Health 1999:8:185-92.

22 Liebenberg L. Thinking critically about Photovoice: achieving Empowerment and social change. Int J Qual Methods 2018;17:1609406918757631.

23 Byrne M. Interviewing as a data collection method. AORN J 2001;74:233-5

24 Fereday J, Muir-Cochrane E. Demonstrating rigor using thematic analysis: a hybrid approach of inductive and deductive coding and theme development. Int J Qual Methods 2006;5:80-92.

25 Catalani C, Minkler M. Photovoice: a review of the literature in health and public health. Health Educ Behav 2010;37:424-51.

26 CPSI. Reducing falls and injuries from falls 2015.

27 Krefting L. Rigor in qualitative research: the assessment of Trustworthiness. Am J Occup Ther 1991;45:214-22.

28 Tobin GA, Begley CM. Methodological rigour within a qualitative framework. J Adv Nurs 2004;48:388-96.

29 Thorne SE. Interpretive description: qualitative research for applied practice. New York, NY: Routledge, 2016.

30 Lincoln YS, Guba EG, Pilotta JJ. Naturalistic inquiry. Beverly Hills, CA: Sage, 1985: 9. 438-9.

31 Sihvonen S, Sipilä S, Taskinen S, et al. Fall incidence in frail older women after individualized visual Feedback-Based balance training. Gerontology 2004;50:411-6.

32 Lord SR, Tiedemann A, Chapman K, et al. The effect of an individualized fall prevention program on fall risk and falls in older people: a randomized, controlled trial. J Am Geriatr Soc 2005;53:1296-304.

33 Somers MF. Spinal cord injury: functional rehabilitation. 2nd edn. Upper Saddle River, N. J.: Pearson Education, 2001.

34 Jørgensen V, Butler Forslund E, Franzén E, et al. Factors associated with recurrent falls in individuals with traumatic spinal cord injury: a multicenter study. Arch Phys Med Rehabil 2016;97:1908-16.

35 Pohl P, Sandlund M, Ahlgren C, et al. Fall risk awareness and safety precautions taken by older community-dwelling women and Men-A qualitative study using focus group discussions. PLoS One 2015;10:e0119630

36 Fast A, Sosner J, Begeman P, et al. Forces, moments, and acceleration acting on a restrained dummy during simulation of three possible accidents involving a wheelchair negotiating a curb: comparison between lap belt and four-point belt. Am J Phys Med Rehabil 1997;76:370-7.

37 Chen W-Y, Jang Y, Wang J-D, et al. Wheelchair-related accidents: relationship with wheelchair-using behavior in active community wheelchair users. Arch Phys Med Rehabil 2011;92:892-8.

38 Kirby RL, Ackroyd-Stolarz SA, Brown MG, et al. Wheelchair-related accidents caused by tips and falls among noninstitutionalized users of manually propelled wheelchairs in nova Scotia. Am J Phys Med Rehabil 1994;73:319-30.

39 Jørgensen V, Roaldsen KS. Negotiating identity and self-image: perceptions of falls in ambulatory individuals with spinal cord injury a qualitative study. Clin Rehabil 2017;31:544-54.

40 Gainforth HL, Latimer-Cheung AE, Davis C, et al. Testing the feasibility of training peers with a spinal cord injury to learn and implement brief action planning to promote physical activity to people with spinal cord injury. J Spinal Cord Med 2015;38:515-25.

41 Ljungberg I, Kroll T, Libin A, et al. Using peer mentoring for people with spinal cord injury to enhance self-efficacy beliefs and prevent medical complications. J Clin Nurs 2011;20:351-8.

42 Garbett R, Mccormack B. The experience of practice development: an exploratory telephone interview study. J Clin Nurs 2001;10:94-102.

43 Guilcher SJT, Munce SEP, Couris CM, et al. Health care utilization in non-traumatic and traumatic spinal cord injury: a population-based study. Spinal Cord 2010;48:45-50.

44 Krause JS, Broderick L. Outcomes after spinal cord injury: comparisons as a function of gender and race and ethnicity. Arch Phys Med Rehabil 2004;85:355-62. 